\title{
Acquiring the Left Periphery of the Modern Greek DP*
}

\section{Theodore Marinis}

\section{Introduction}

Generative research on language acquisition within the Principles and Parameters framework based on the Functional Parameterisation Hypothesis (cf. Atkinson, 1992) has provided a formal account of the acquisition of lexical vs. functional categories. Accordingly, early child grammar consists of lexical-thematic categories. This idea originates in Lebeaux (1988) and has been further developed among others by Guilfoyle \& Noonan (1992), Radford (1990), Tsimpli (1992) and Powers (1996), who have claimed that early child speech lacks functional categories. More recently, Platzack (1999-a), adopting Rizzi's (1997) ideas for an articulated structure of the Left Periphery of the clause, developed the idea that normal developing children (along with children with SLI, adults acquiring a second language and Broca's aphasic patients) display a non target-like production of the syntax of the highest structural level, the CP layer (the Left Periphery of the clause), while their production of lower structural levels, the IP layer and the VP layer (the Core Domain of the clause), is target-like.

This paper aims to contribute to this issue by extending the discussion of the acquisition of the Left Periphery to the nominal domain. The analysis of acquisition data from Greek normal developing children will show that children pass through a stage in which they do not use structures involving the Left Periphery of the nominal domain, while they do use structures involving the Core Domain (the FP layer and the NP layer). This will be taken as evidence for the unavailability of the Left Periphery of the DP in early child speech.

* This paper was presented in the Peripheries Conference, at York, in September 2000. I would like to thank the audience of the conference as well as H. Clahsen and C. Felser for helpful comments. 
Furthermore, it will be shown that children pass through a stage in which there is no evidence for the FP (which corresponds to the IP layer in the clausal domain). This observation is similar to observations made by Clahsen, Eisenbeiss \& Penke (1996) and Eisenbeiss (2000) for the acquisition of the DP in German. The extension of Rizzi's views for the Left Periphery of the clausal domain to the Left Periphery of the nominal domain provides a principled account for the development of the acquisition of the DP, which, unlike previous approaches to the same issue, such as Radford (1990), Clahsen, Eisenbeiss $\&$ Penke (1996) and Eisenbeiss (2000), explains the specific developmental route based on the different types of information encoded in each one of the three structural layers.

The paper is organised as follows: Section 2 is concerned with Rizzi's (1997) analysis of the Left Periphery of the clausal domain and with Platzack's (1999-b) idea of multiple interfaces. Section 3 extends the tri-partition of the clausal domain to the tri-partition of the nominal domain and provides an analysis of phenomena that are related to the Core Domain and Left Periphery of the nominal domain in Modern Greek, namely case and number marking in nouns, the Possessive Construction and Determiner Spreading. Data on the acquisition of these phenomena are presented in Section 4. Finally, Section 5 summarises the results and relates them to data from the acquisition of Clitic Left Dislocation, which is related to the Left Periphery of the CP in Modern Greek.

\section{The Left Periphery of the clause}

The idea that the structural representation of the clause consists of three layers - a VP, an IP and a CP layer - has been widely accepted since the mid 1980s. Accordingly, the VP is the lexical layer headed by the verb, the IP the inflectional layer headed by functional heads corresponding to morphological specifications of the verb that are responsible for the licensing of features such as case and agreement, and the $\mathrm{CP}$ is the complementiser layer hosting topics and operator-like elements such as interrogative pronouns, relative pronouns and focalised elements. In line with the tri-partition of the clause structure in three domains, Platzack (1999-b) developed the idea of multiple interfaces, according to which each one of the three structural domains corresponds to an interface level: the level of the Thematic Form corresponding to the VP layer, the level of Grammatical Form corresponding to the IP layer, and the level of Discourse Form corresponding to the CP layer, as shown in (1) 
below. In this view, there is a one-to-one correspondence between the composition of the clause and the type of information expressed in each domain; the interpretative mechanisms are fed at particular points in the computation through multiple interfaces as the derivation unfolds.

\title{
Left Periphery
}

(1)

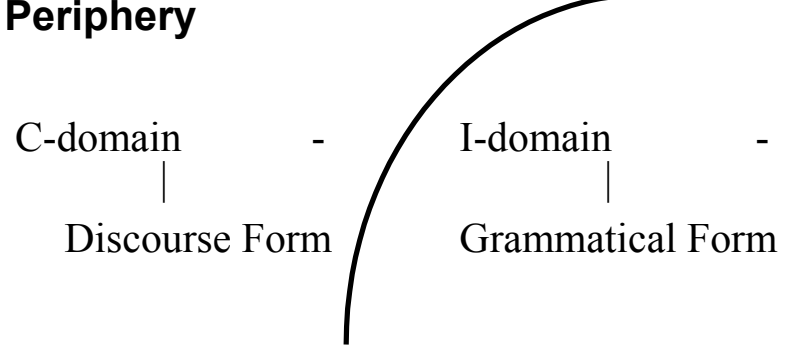

\author{
V-domain \\ Thematic Form \\ Core Domain
}

As far as the Left Periphery, i.e. the CP layer, is concerned, Rizzi (1997) has suggested that the complementiser system consists of two parts, each one of which expresses a different type of information. The one part, ForceP, is facing outwards, as shown in (2) below, and expresses whether the sentence is interrogative, declarative, imperative, exclamative, etc. The other part, FinP, is facing inwards, expresses finiteness and is related to tense and mood in the lower inflectional system.

\section{(2) $\left[\right.$ ForceP $\left[\operatorname{Force}^{0}\left[\ldots\left[\operatorname{Fin}\left[\operatorname{Fin}^{0}\left[\mathrm{IP}\left[\mathrm{I}^{0}\left[\mathrm{VP}\left[\mathrm{V}^{0}\right]\right]\right]\right]\right]\right]\right]\right]$}

Moreover, Rizzi has suggested that the $\mathrm{C}$ system is related to the functions of topicalisation and focalisation. Topicalisation is expressed through a TopP projection headed by a Top head, whose specifier is the topic and its complement is the comment, as shown in (3a) below; focalisation is expressed through a FocP projection headed by a Foc head, whose specifier is a focus while its complement is the presupposition, as shown in ( $3 \mathrm{~b}$ ) below.
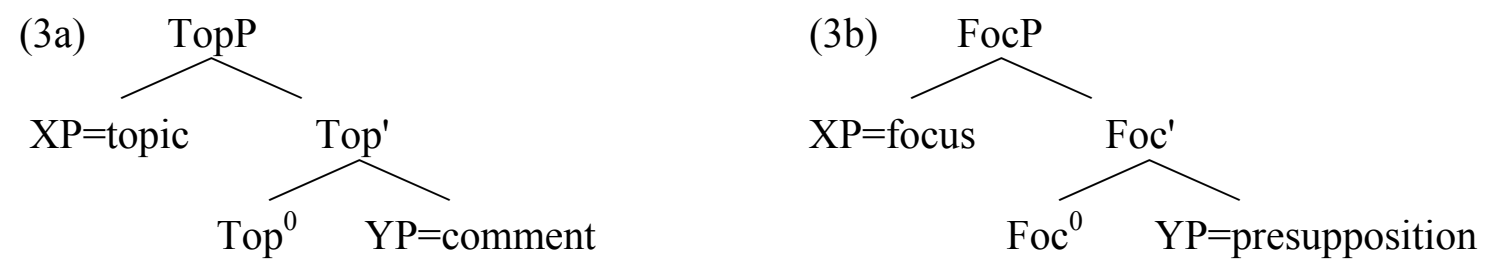

The TopP and FocP layers are present only when a constituent bears topic or focus features. In this case they are sandwiched between ForceP and FinP, as shown in (4) below. 


\section{(4) ForceP - (TopP) - (FocP) - FinP - IP - VP}

Moreover, given the possibility for a sentence to have two topics in the sense that the complement of a topic head (the comment) may be in a topic-comment relation with another constituent, the TopP can undergo free recursion. The same is not true for the FocP, since the complement of a focus head (the presupposition) cannot function as the focus of some other constituent.

\subsection{Acquiring the Left Periphery of the clause}

Numerous studies have shown a dissociation of the acquisition of phenomena, which are related to higher structural levels, like the CP- and the TP-layer and the acquisition of phenomena, which are related to lower structural levels: the IP- and VP-layer. Data supporting the idea that a full-fledged C-system is not active early in development has been provided in Penner \& Mueller (1992), Mueller, Crysmann \& Kaiser (1996) among others. Similar results have been reported in Wexler (1996) for Danish, Dutch, English, Faroese, French, German, Hebrew, Irish, Norwegian and Swedish normal developing children, and in Rice \& Wexler (1996) for children with SLI.

More recently, Platzack (1999-a) has viewed the results of such studies in the context of Rizzi's analysis of the Left Periphery, suggesting that children acquiring their native language (along with children with SLI, adults acquiring a second language and Broca's aphasic patients) ${ }^{1}$ have difficulties with structures involving the Left Periphery, but not with structures involving lower structural layers (the IP- and the VP-layer). More specifically, Platzack showed that in Swedish and German, these groups of speakers do not adhere to the constraint that the main clause must contain a finite verb, violate verb second, omit subjects after finite verbs and omit wh-words. These structures are associated with the C-domain. Contrary to this observation, the same groups of speakers do not seem to have difficulties with phenomena that are associated with the V-and I-domain: there are no word-order violations in infinitival verb - direct object, and verbal particle - direct object constructions.

1 For similar observations on the comprehension and production of Broca's aphasics see Grodzinsky (2000). 


\section{The Left periphery of the nominal domain}

Since Horrocks \& Stavrou $(1986 ; 1987)$ and Abney $(1987)$, the inclusion of argumental nominal phrases into a DP shell is a common ground. The DP layer in the nominal domain parallels the CP layer in the clausal domain. Further, Rizzi's idea of an articulated structure of the CP has been extended to the structure of the DP (Haegeman, 2000). Accordingly, the DP in the nominal domain parallels the FinP in the clausal domain: the DP encodes referentiality, i.e. it anchors nominal reference, whereas the FinP encodes finiteness, i.e. it anchors the event in time. Both the DP and the FinP serve the function of linking (a referent or an event) to the speaker's universe of discourse. Topicalisation and focalisation may be represented through a TopP and FocP, as in the clausal domain.

As far as the specifier of the DP is concerned, there is a consensus that in Modern Greek (MG) and in Hungarian this is a non-thematic position which serves as an escape hatch for movement involving topicalisation and focalisation ${ }^{2}$ (see Horrocks \& Stavrou, 1987; Szabolsci, 1994; Haegeman, 2000).

The parallelism between the clausal and the nominal domain is not restricted to the maximal projection of the nominal domain. Several analyses have suggested the presence of a functional category within the nominal domain which is parallel to the IP in the clausal domain and is related to nominal inflection (see Ritter, 1991).

Karanassios (1990) was the first to propose an internal functional projection within the DP in MG. Since then, several studies have adopted such a functional projection, however, both the label and its featural content have been a matter in dispute. Departing from the labelling issue, there are three predominant views for the feature specification of this functional projection: according to Karanassios (1990) and Stavrou (1996), it hosts the number feature of the nominal phrase, according to Tsimpli \& Stavrakaki (1999) it hosts case and phi-features, and in Alexiadou \& Stavrou (1997) and Alexiadou (1999) it is related to number and case.

In the present paper, the last view will be adopted, which is heavily based on the morphological properties of the DP in MG, as in Ralli (1994, 1998). According to Ralli, case and number in MG are features of the inflectional affix, while gender is an inherent feature of the noun stem. Given that, the gender feature is instantiated in the terminal node

2 Or possibly Spec,TopP and Spec,FocP, respectively. 
$\mathrm{N}^{0}$, while the features of number and case show up in the head of the intermediate projection.

Given the parallelism between the DP and the CP, the NP is the lexical layer of the nominal domain, which is parallel to the VP. The FP is the inflectional layer of the nominal domain, which is parallel to the inflectional layer of the clausal domain, the IP. Finally, the DP is parallel to the CP and represents the Left Periphery of the nominal domain, as shown in (5) below.

\section{(5)Left Periphery}

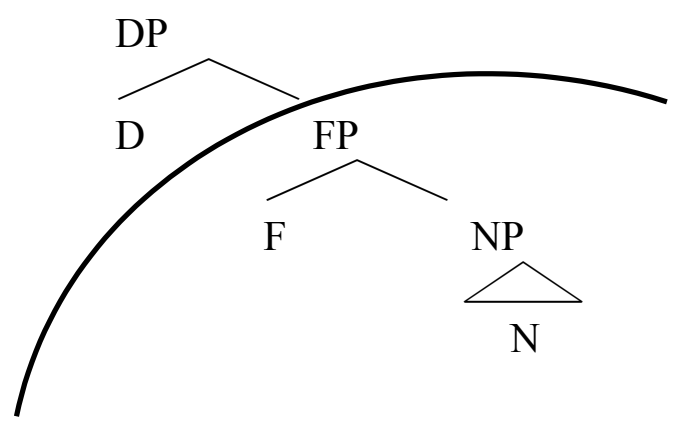

\section{Core Domain}

The next sections will deal with phenomena which are related to the Core Domain and the Left Periphery of the MG nominal domain, i.e. case and number marking in nouns, the Possessive Construction and Determiner Spreading.

\subsection{Case and Number Marking in Nouns}

As shown in the previous section, FP belongs to Core Domain of the DP and is related to case and number marking. Let us now look more closely to morphological marking in nouns.

MG has a rich nominal inflectional system with four cases (nominative, accusative, genitive, vocative), two numbers (singular, plural), three genders (masculine, feminine, neuter) and eight inflectional classes (Ralli 1998). Nouns are marked for case, number and gender, but there is a relatively high degree of syncretism, which is not equal in all inflectional classes (ICs): based on the number of different word-forms in the singular, nouns have traditionally been divided into two main classes, diptota which have a two-way distinction (two different word-forms) and triptota which have a three-way distinction (three different word-forms) (Kourmoulis, 1964). IC 1 corresponds to the class of triptota, while ICs 2 to 8 to the class of diptota. The relation between ICs, gender, case contrast and 
the number of different word-forms in the paradigm of the singular is given in Table 1 below.

Table 1: IC, gender, case contrast and number of singular word-forms

\begin{tabular}{|c|c|c|c|}
\hline IC & Gender & Case Contrast & word-forms \\
\hline IC 1 & & NOM Vs. GEN Vs. ACC (vs. VOC) & three (four) \\
\hline IC 2 & & NOM Vs. GEN/ACC/VOC & \\
\hline $\begin{array}{l}\text { IC } 3 \\
\text { IC } 4\end{array}$ & feminine & & \\
\hline $\begin{array}{l}\text { IC } 5 \\
\text { IC } 6 \\
\text { IC } 7 \\
\text { IC } 8\end{array}$ & neuter & GEN vs. NOM/ACC/VOC & two \\
\hline
\end{tabular}

Within the class of triptota (IC 1), nouns have three to four different word-forms, whereas within the class of diptota two, e.g. in IC 2 and IC 3 there is a distinction between a wordform ending on the stem vowel vs. on the suffix $-s$, as shown in Table 2 below.

Table 2: Noun Inflection: triptota vs. diptota in the singular

\begin{tabular}{|c|c|c|c|c|}
\hline & IC 1 & IC 2 & & IC 3 \\
\hline Nom. & anthrop-os & baba-s & Nom & \\
\hline Gen. & anthrop-u & & Acc. & mama \\
\hline Acc. & anthrop-o & baba & Voc. & \\
\hline Voc. & anthrop-e & & Gen. & mama-s \\
\hline
\end{tabular}

In the light of these facts, nouns ending in the stem vowel are assumed to represent unmarked forms of the inflectional paradigm of nouns (Christofidou, 1998; Stephany, 1997; Marinis, 2000-a). ${ }^{3}$

3 According to Thomadaki (1994), nouns in IC 2 are specified by the feature [ \pm NOM], nouns in ICs 3 to 8 with the feature $[ \pm$ GEN], and nouns in IC 1 with the features [ \pm NOM] and [ \pm GEN]. 
As discussed in the previous section, morphological marking in nouns is related to the FP layer of the nominal domain. Within the analysis of Alexiadou (1999) case/number checking takes place through movement of the noun from $\mathrm{N}^{0}$ to $\mathrm{F}^{0}$, as shown in (6a) vs. (6b) below.

(6a)

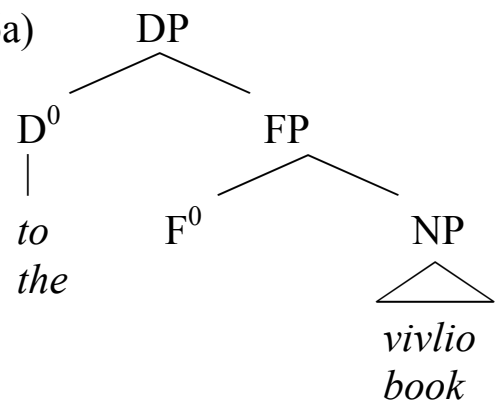

$(6 b)$

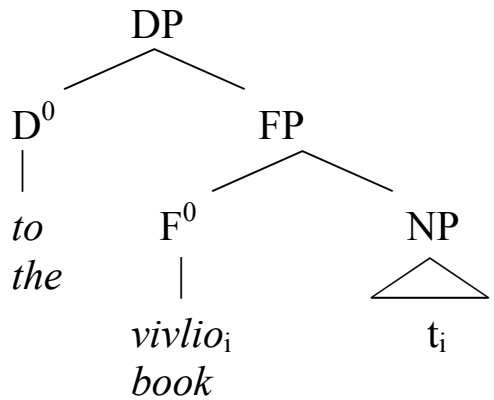

$\mathrm{N}^{0}$ to $\mathrm{F}^{0}$ movement is an instance of movement within the Core Domain of the DP. If this is operative in child speech, we expect children to use nouns with case/number marking. If, on the other hand, children do not apply this type of movement, the prediction is that they will use nouns in the unmarked form, i.e. ending on the stem vowel. Finally, if there is a dissociation between the acquisition of the Core Domain and the Left Periphery of the DP, we expect children to pass through a stage in which they use nouns marked for case/number, while phenomena which are related to the Left Periphery of the DP are not present in their speech. The next two sections illustrate two constructions involving the Left Periphery of the DP, the Possessive Construction and Determiner Spreading.

\subsection{The Possessive Construction}

The Possessive Construction in MG displays two linearisations, Possessum $>$ Possessor and Possessor $>$ Possessum, as shown in examples (7a) and (7b) below. Both possessor and possessum have to be preceded by the definite article, i.e. the Possessive Construction requires the use of multiple determiners. Finally, within the possessor DP, both the determiner and the noun are marked for genitive.
(7a) Pira to vivlio tu Niku. took the-ACC book-ACC the-GEN Niku-GEN 'I took Niko's book.' 


\section{(7b) Pira tu Niku to vivlio. $\quad$ (Possessor $>$ Possessum) took the-GEN Niku-GEN the-ACC book-ACC 'I took Niko's book.'}

Crucially, example (7b) above involves either focalisation or topicalisation. In the case of focalisation, the DP in genitive 'tu Niku' has focal stress and it is the focus of the complex DP. In the case of topicalisation, there is no stress on the DP 'tu Niku' which is the topic of the complex DP whereas the DP 'to vivlio' is the comment.

There are two predominant analyses of the MG Possessive Construction: a) the analysis of Horrocks \& Stavrou (1987) and Alexiadou \& Stavrou (1998), and b) the analysis of Alexiadou (1999). In Horrocks \& Stavrou (1987) and Alexiadou \& Stavrou (1998), possessors are base generated post-nominally as the complement of the noun, as shown in (8a) below, and the base word-order corresponds to the word-order Possessum $>$ Possessor in example (7a) above. Pre-nominal genitives, i.e. the order Possessor $>$ Possessum, are the result of movement of the possessor to the specifier of the DP. ${ }^{4}$ This is shown in $(8 \mathrm{~b})$ below, and corresponds to example (7b) above.

(8a)

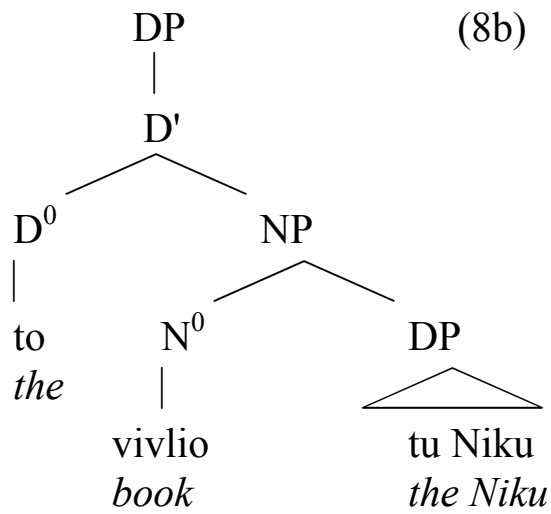

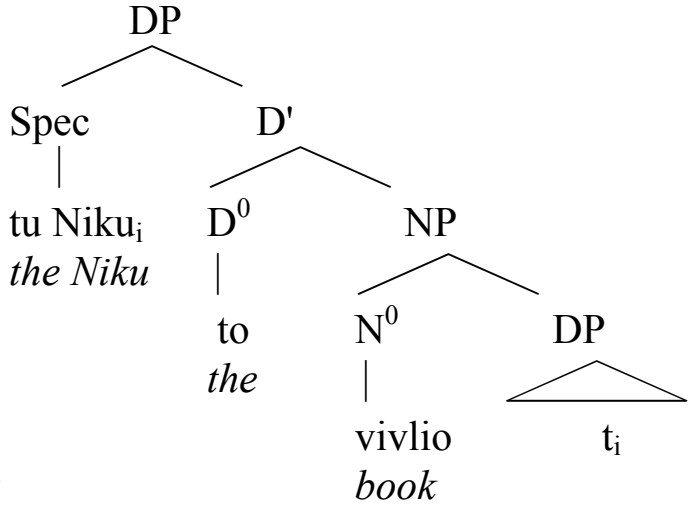

Movement of the possessor to Spec,DP is not motivated for case assignment of the possessor. ${ }^{5}$ It is an $\mathrm{A}^{\prime}$-Movement for focalisation or topicalisation.

4 Or possibly to the specifier of a FocP in the case of focalisation or TopP in the case of topicalisation.

5 Checking of genitive case does not involve movement, but rather takes place in the base position, similarly to case checking in the clausal domain, as in Alexiadou \& Anagnostopoulou (1995). 
In the analysis of Alexiadou (1999), on the other hand, who distinguishes inalienable from alienable possessors, alienable possessors ${ }^{6}$ are licensed by an external functional head, i.e. Poss, as illustrated in (9) below.

(9)

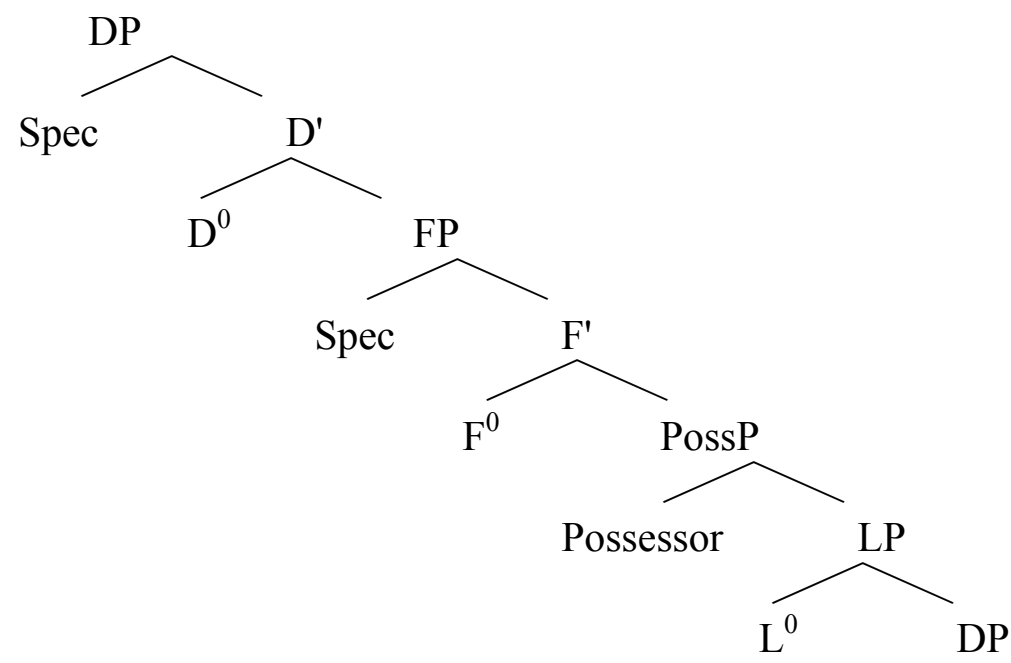

Alienable possessors, like the ones in examples (7a) and (7b) above, are analysed by Alexiadou (1999) in the following way: the possessor is base-generated/merged within the PossP and the possessum within the lexical projection (LP), as shown in (10a) below. The possessum moves to $\mathrm{F}^{0}$, in order to check number and case (see Section 3.1), as shown in (10b) below. The result of this movement is the order Possessum $>$ Possessor.

(10a)

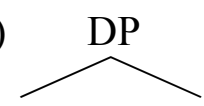

$\mathrm{D}$<smiles>[CH]1C[CH]C1</smiles>
to $\mathrm{F}$ the (10b)
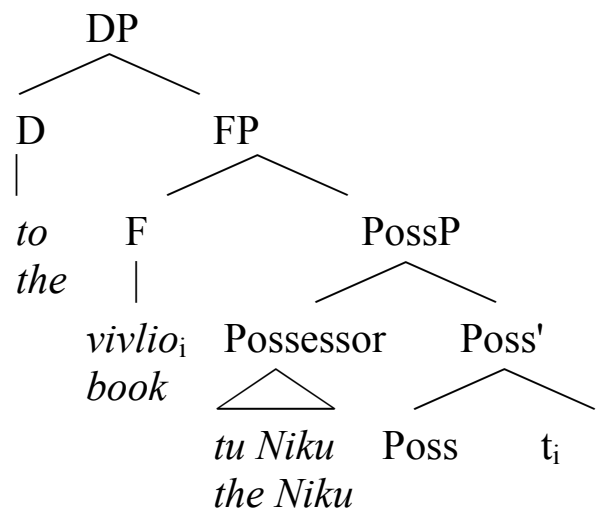

vivlio

book

6 In this paper, I will focus on the acquisition of alienable possessors, due to the lack of data from inalienable possessors in the corpora used. 
The order Possessor $>$ Possessum is, like in the analysis of Horrocks \& Stavrou (1987) and Alexiadou \& Stavrou (1998), the result of a subsequent movement of the possessor to Spec,DP, for focalisation or topicalisation, as illustrated in (11) below.

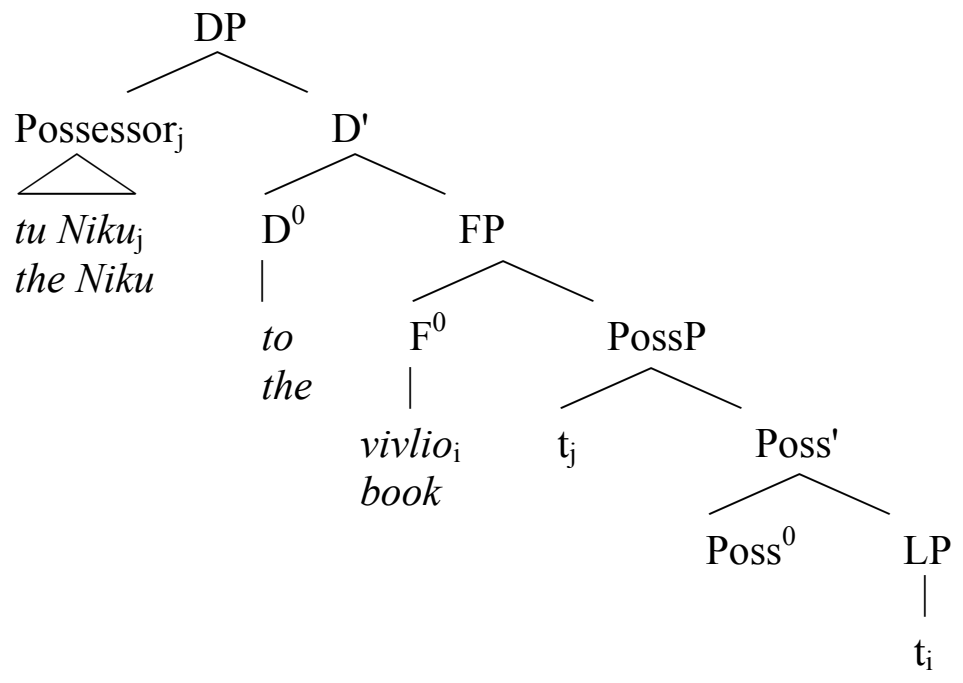

The next section deals with a further phenomenon, which involves the Left Periphery of the DP, Determiner Spreading.

\subsection{Determiner Spreading}

Determiner Spreading (DS) is an instance of adjective modification. When used attributively, adjectives in definite DPs precede the noun in MG, as shown in example (12) below.

$$
\begin{aligned}
& \text { Aghorasa to meghalo spiti. } \\
& \text { bought the big } \\
& \text { 'I bought the big house.' }
\end{aligned}
$$

In the phenomenon of DS, definite articles precede both the adjective and the noun, as in example (13) below, or even every adjective modifying the noun, when the noun is modified by more than one adjective, as in example (14) below.

$$
\begin{aligned}
& \text { Aghorasa to meghalo to spiti. } \\
& \text { bought the big } \\
& \text { 'I bought the big house.' }
\end{aligned}
$$




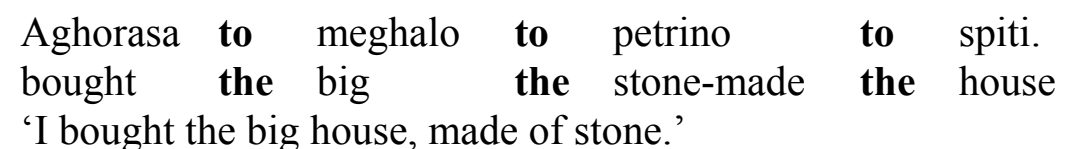

As far as the interpretation of DPs with DS is concerned, the majority of studies on DS (Androutsopoulou, 1994; 1995; Alexiadou \& Wilder, 1998) have neglected the fact that DPs with DS do not have exactly the same reading as DPs without. The only exception is Kolliakou's (1998) study, who describes the difference between adjectival modification with and without DS as follows: adjectival modification with a single definite article may have either a restrictive or a non-restrictive interpretation; adjectival modification involving DS, on the other hand, may only have a restrictive reading. Consider examples (15a) and (15b) below.

a O dhiefthindis dhilose oti i ikani erevnites tha $\begin{aligned} & \text { eprepe } \\ & \text { should }\end{aligned}$
the director declared that the competent researchers fut-prt
n' apolithun.
subj-prt ${ }^{8}$ fired.
'The director declared that the competent researchers should be fired.'
(restrictive and non-restrictive meaning)

b $\mathrm{O}$ dhiefthindis dhilose oti $\mathbf{i}$ ikani $\mathbf{i}$ erevnites tha the director declared that the competent the researchers fut-prt eprepe n' apolithun. should subj-prt fired 'The director declared that the competent researchers should be fired.' (only restrictive meaning)

(Kolliakou 1998:5)

The DP without DS $i$ ikani erevnites = the competent researchers in example (15a) above may have two interpretations, a restrictive and a non-restrictive. In the non-restrictive interpretation, we have information about only one group of researchers, those who are competent and should be fired (possibly due to financial difficulties of the company), i.e. there are no cues as to whether there is any other group of researchers which should not be fired. In the restrictive interpretation, on the other hand, the competent researchers are singled out from a bigger group of researchers and only the competent ones should be fired

\footnotetext{
fut-prt $=$ future particle

subj-prt $=$ subjunctive particle
} 
(maybe because they have some secret plan against the company). In the restrictive interpretation, it is implied that other researchers (who are for example not competent and are, therefore, not dangerous for the company) should not be fired. In example (15a) above, prosody disambiguates between the two readings. If the adjective is stressed, we get the restrictive interpretation; if stress is on the noun, we get the non-restrictive one. The DP involving DS in (15b) above, on the other hand, allows only for the restrictive interpretation. Thus, DS is felicitous in only a subset of the contexts of adjectival modification involving single definite articles.

With respect to the distributional properties of DS, in the presence of extra definite articles, more than one order of the DP constituents is possible, as shown in examples (16a)-(16e) below, but in the absence of extra definite articles, the order is rigid, as shown in examples (17a) and (17b) below.

(16) a Aghorasa to meghalo to petrino to spiti. bought the big the stone-made the house

b Aghorasa to meghalo to spiti to petrino. bought the big the house the stone-made

c Aghorasa to petrino to spiti to meghalo. bought the stone-made the house the big

d Aghorasa to spiti to meghalo to petrino. bought the house the big the stone-made

e Aghorasa to spiti to petrino to meghalo. bought the house the stone-made the big 'I bought the big house, made of stone.'

$\begin{array}{lllll}\text { a Aghorasa to } & \text { meghalo } & \text { petrino } & \text { spiti. } \\ \text { bought } & \text { the big } & \text { stone-made } & \text { house } \\ \text { b* Aghorasa to } & \text { spiti } & \text { meghalo } & \text { petrino. } \\ \text { bought the house } & \text { big } & \text { stone-made } \\ \text { 'I bought the big house, made of stone.' }\end{array}$

Moreover, in the presence of some but not all possible definite articles, word-order variation is restricted, as in examples (18a) and (18b) below. The noun can be used without an extra definite article, when it does not precede adjectives, as in example (19a) below, and when it precedes some but not all adjectives, as in example (19b) below. 
(18)

\begin{tabular}{cllll} 
a* Aghorasa to spiti meghalo to petrino. & \multicolumn{2}{c}{ m } \\
bought & the house big the stone-made \\
b* Aghorasa to spiti to meghalo petrino. & to \\
bought the house the big & stone-made \\
'I bought the big house, made of stone.'
\end{tabular}

(19)
a Aghorasa to meghalo to petrino spiti. bought the big the stone-madehouse
b Aghorasa to meghalo spiti to petrino. bought the big house the stone-made 'The big house, made of stone.'

There are two main analyses of DS within the generative framework. ${ }^{9}$ Androutsopoulou (1994; 1995) suggests that adjectives head APs which project within the extended projection of the NP, similarly to Abney (1987). Each definite article heads its own functional projection (DefP), as shown in (20) below.

$$
\begin{aligned}
& \text { [DP [DEFP0 to [AP1 meghalo [DEFP1 to [AP2 petrino [DEFP2 to [NP } \quad \text { spiti }]]]]]] \\
& \text { the big the stone-made the house }
\end{aligned}
$$

'The big house, made of stone.'

DefPs are agreement projections hosting agreement features and a definiteness feature $[+\mathrm{def}] .{ }^{10}$ However, the locus of definiteness and referentiality is $\mathrm{D}^{0}$, and not the heads of the DefPs. Since definite articles are generated in $\operatorname{Def}^{0}, \mathrm{D}^{0}$ is empty. In order for the definite article to acquire its semantic force, it has to raise overtly or covertly to $\mathrm{D}^{0}$. The availability of different word-orders is, in this analysis, the result of movement of DefPs to specifiers of higher DefPs, movement which is motivated for the checking of [ + def].

Although this analysis describes the phenomenon of DS adequately, it suffers from a couple of empirical and conceptual drawbacks. On theoretical grounds, it is not clear what the nature of the [+def] feature is. It is hosted in an agreement projection and not in the functional projection that is the locus of definiteness, and its only purpose is to trigger movement. Moreover, on empirical grounds, this analysis cannot capture the word-orders given in examples (21a) and (21b) below, which should derive from (20) above.

\footnotetext{
9 But see Kolliakou (1998) for the analysis of DS within the framework of HPSG.
}

10 In this analysis, [+def] is a syntactic and not a semantic feature. 
(21) a To petrino to meghalo to spiti.

the stone-made the big the house

'The big house made of stone.'

b To petrino to meghalo spiti.

the stone-made the big house

'The big house made of stone.'

Examples (21a) and (21b) above cannot be captured in this analysis, because the AP petrino should not be able to move to Spec, $\mathrm{DEFP}^{0}$ without pied-piping the NP spiti.

The analysis adopted in this paper builds on the analysis of Alexiadou \& Wilder (1998), which will be slightly modified. Alexiadou \& Wilder analyse APs in DS as full clauses with a CP and an IP projection. This idea is based on Kayne's (1994) analysis of adjectives modifying nouns as Reduced Relative Clauses. Extending Kayne's analysis of Reduced Relative Clauses, APs are, in Alexiadou \& Wilder, predicates of a CP, which is the complement of D, as shown in (22) below. The surface word-order D-Adj-N is the result of movement of every AP to the specifier of the corresponding CP, as shown in (23) below. Movement is triggered by an A-feature of $\mathrm{C}$.

(22) $[\mathrm{DP} D[\mathrm{CP}[\mathrm{IP}$ DP AP $]]]$

(Alexiadou \& Wilder 1998)
(23) $\left[\mathrm{DP} 3\right.$ to $_{1}\left[\mathrm{CP} 1{ }_{\mathrm{AP} 1} \text { meghalo }\right]_{\mathbf{i}}\left[\mathrm{DP} 2 \mathrm{to}_{2}\left[\mathrm{CP} 2\left[\mathrm{AP2} \mathbf{p e t r i n o}_{\mathbf{j}}\left[\mathrm{DP}_{3}\right.\right.\right.\right.$ to $_{3}$ spiti $\left.\left.\left.\left.] \mathbf{t}_{\mathbf{j}}\right]\right] \mathbf{t}_{\mathbf{i}}\right]\right]$ the big the stone-made the house
'The big house, made of stone.'

The other possible word-orders are the result of further movements of DPs to the specifier of higher DPs, as shown in (24) below. Such movements are triggered by an optional strong D-feature of D.

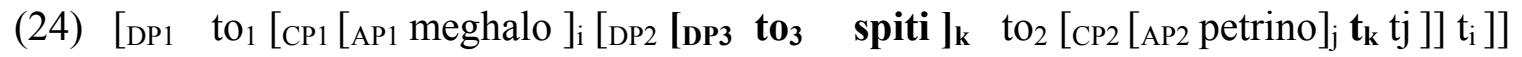
the big the house the stone-made 'The big house, made of stone.'

This analysis not only captures the word-order possibilities obtained in the analysis of Androutsopoulou, but can also account for the word-order possibilities that could not be captured in Androutsopoulou's analysis, such as in examples (21a) and (21b) above. This is 
achieved through the availability of different sequences of the operation merge. Consider (25) below, which corresponds to example (21a) above.

(25) $\left[\mathrm{DP} 1 \mathrm{to}_{1}[\mathrm{CP} 1[\mathrm{AP} 1\right.$ the petrino $]_{i}\left[{ }_{D P} 2 t_{2}\left[\mathrm{CP} 2\left[_{\mathrm{AP} 2} \mathbf{m e g h a l o}_{\mathrm{j}}[\mathrm{DP} 3\right.\right.\right.$ stone-made the big

to $_{3} \quad$ spiti] $\left.\left.\mathbf{t}_{\mathbf{j}}\right] \mathbf{t}_{\mathbf{i}}\right]$ ]]

the house

The modification of the analysis of Alexiadou \& Wilder regards the optional movement of DPs to higher DPs (or to a FocP or a TopP). In our view, this movement can be better accounted for if it is triggered by the presence of a Peripheral feature (see Chomsky, 1998), a topic or focus feature, rather than an optional strong D-feature. Under this assumption, a topic or focus feature comes into the numeration, each time topic or focus is intended (see Marinis, 2000-a). There are two conceptual advantages for the use of a topic and focus feature instead of an optional strong D-feature: a) this movement is not any longer optional, since a topic or focus feature appears in the numeration, when topicalisation or focalisation are involved and then movement must take place, and b) movement for the checking of a topic or focus feature can capture not only movement to Spec,DP in DS, but every movement that involves topicalisation or focalisation, e.g. movement of the possessor to Spec,DP in the Possessive Construction.

\section{The Data}

This study is based on the speech of 5 monolingual Greek children growing up in Athens, Christos, Spiros, Janna, Mairi and Maria. The age of the children, the number of recordings and the number of utterances produced by each child are given in Table 3 below.

Table 3: Data

\begin{tabular}{|c|c|c|c|c|c|}
\hline & Christos & Spiros & Janna & Mairi & Maria \\
\hline Age & $1 ; 7-2 ; 8$ & $1 ; 9$ & $1 ; 11 / 2 ; 5 / 2 ; 9$ & $1 ; 9 / 2 ; 3 / 2 ; 9$ & $2 ; 3 / 2 ; 9$ \\
\hline Nr of recordings & 69 & 2 & 9 & 12 & 5 \\
\hline Nr of utterances & 12,383 & 443 & 1,357 & 4,154 & 3,074 \\
\hline
\end{tabular}


The speech of Christos comes from the Christofidou Corpus, and the speech of the other four children from the Stephany Corpus, which is available in the CHILDES Database (MacWhinney \& Snow, 1985).

The recordings of Christos took place on a weekly basis and sometimes on a daily basis and cover the age of $1 ; 7$ to $2 ; 8$. Due to the density of the recordings it is possible to make a fine grained analysis of the development of his speech. The recordings of the children in the Stephany Corpus cover the age of $1 ; 9$ to $2 ; 9$. The corpus has been collected at three different points in time with approximately six months distance between them. Consequently, data from the children in the Stephany Corpus can bring insight into the language abilities of the children only at particular points in time; it is not possible to trace the development that took place between them. Thus, developmental issues will be based on the data from Christos, to which the data from the other four children will be matched.

\subsection{The emergence of Case and Number Marking in Nouns}

Case and number marking in nouns is related to the FP layer, which belongs to the Core Domain of the DP (see Section 3). The use of case and number marking in nouns can thus provide evidence for the availability of the inflectional layer of the nominal domain.

The acquisition of noun morphology in the Christofidou and the Stephany Corpus has been studied in detail in Christofidou \& Stephany (1997), Kilani-Schoch, et al. (1997), Stephany (1997) and Christofidou (1998). The data presented in this section are based on both these studies and my analysis of the corpora.

Two types of data are important for the present study: a) the emergence of case and number marking in nouns, and b) the contrastive use of case and number marking in nouns. The emergence of case/number marking is defined as the first use of case/number marking. Contrastive use is defined as the use of a word-form with a specific case/number marking as opposed to another word-form with a different case/number marking, for example a nominative form of the noun as opposed to an accusative one.

The most complete picture as far as case/number marking is concerned could be obtained in the recordings of Christos due to the high density of the recordings and the large amount of data. The first noun forms used by Christos do not show case and number marking. From 1;7 to 1;11 all nouns end on the stem vowel, which is the unmarked form of 
the inflectional paradigm (see Section 3.1). Case marking emerges at the age of 1;11 prior to number marking. The first inflectional suffix attested is the MASC/NOM/SG suffix $-S$ at $1 ; 11.0$ with nouns from IC 2. Contrastive use of the suffix $-S$ vs. stem vowel (NOM vs. ACC) is attested for the first time in the next session $(1 ; 11.10)$. Moreover, in the following recording $(1 ; 11.13)$, Christos overgeneralises the suffix $-s$ to foreign names, e.g. Mickey, Pluto. ${ }^{11}$

Genitive case marking emerges with the FEM/GEN/SG suffix $-s$ at 1;11.19 with nouns belonging to the IC 3. Initially it is used with one lexeme, i.e. mama = mom. Despite its limited use to one lexeme, the FEM/GEN/SG suffix $-s$ is used contrastively to NOM and ACC. ${ }^{12}$ Evidence for genitive case marking with masculine nouns from IC 2 appears at 2;0.16. Christos uses the MASC/NOM/SG marker $-s$ contrastively to GEN with one lexeme, i.e. papu $=$ grandpa . The MASC/GEN/SG suffix $-u$ from IC 1 emerges at 2;4.1 and is initially used consistently only with one lexeme, i.e. Christos.

As far as number marking is concerned, the first nouns in plural appear at the age of 1;9.3 in the speech of Christos. However, as Christofidou (1998) notes, 'these plurals come as standard answers to standard pictures of a book that has been used very often as a basis for conversation' (p.5). Moreover, these words are used only in the plural. Between 1;10 and 2;4, plural noun forms appear: a) as instances of imitation, b) wrongly in contexts requiring singular, c) functionally ambiguous, or d) correctly, but not contrastively. Contrastive use of plural vs. singular noun forms appear for the first time in 2;4.12. However, at the same age, Christos still uses plural forms interchangeably with singular ones. It is only one month later, at the age of 2;5 that Christos stops using plural forms interchangeably with singular ones. Table 4 below summarises the findings from case and number marking in the speech of Christos.

In the Stephany Corpus, the child with the lowest MLU, Janna, passes through a similar stage with Christos: at the age of $1 ; 11$, all nouns in her speech end in the stem vowel. At that stage there is no evidence for case and number marking in nouns.

11 See Theophanopoulou-Kontou (1973) for similar results using experimental data.

12 Theophanopoulou-Kontou (1973) has observed in her data that the FEM/GEN/SG suffix $-S$ is the first suffix marking genitive to be acquired. 
Table 4: Development of Case and Number marking by Christos

\begin{tabular}{ll}
\hline \multicolumn{1}{c}{ Age } & Case and Number Marking \\
\hline $1 ; 7-1 ; 11$ & nouns ending on the stem vowel \\
$1 ; 11$ & first use of $-S$ MASC/NOM/SG (IC 2) \\
$1 ; 11.10$ & contrastive use of $-S$ MASC/NOM/SG vs. ACC, VOC (IC 2) \\
$1 ; 11.19$ & contrastive use of $-S$ FEM/GEN/SG vs. NOM, ACC (one lexeme) (IC 3) \\
$2 ; 0.16$ & contrastive use of $-S$ MASC/NOM/SG vs. GEN (one lexeme) (IC 2) \\
$2 ; 4.1$ & consistent use of $-u$ MASC/GEN/SG (one lexeme) (IC 1) \\
$2 ; 4.12$ & contrastive use of SG/PL \\
$2 ; 5$ & SG/PL not interchangeable \\
\hline \hline
\end{tabular}

In the recordings of the children available in the Stephany Corpus it is not clear if case marking emerges prior to (as in the speech of Christos), simultaneously with, or after number marking. According to Stephany (1997), 'case differences between unmarked singular accusative forms and the marked nominative of masculine stems as well as the genitive of the three genders may either develop later than or simultaneously with number distinctions' (Stephany 1997:224).

With respect to case marking, Spiros marks at the age of $1 ; 985 \%$ of the NOM/MASC/SG nouns with the suffix -os (IC 1), Mairi marks at 1;9 50\% of masculine stems for nominative (IC 1,2) and Maria starts marking masculine stems for nominative only after $2 ; 3$. At the age of $2 ; 3$, Janna seems to have knowledge of nominative singular marking of masculine stems (Stephany 1997:223). The development of case and number marking in the speech of the children under investigation is summarised in Table 5 below.

Table 5: Emergence of case and number marking

\begin{tabular}{|c|c|c|c|c|c|}
\hline & Christos & Spiros & Janna & 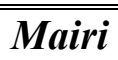 & Maria \\
\hline no case/number marking & $1 ; 7-1 ; 10$ & - & $1 ; 11$ & - & - \\
\hline case marking & $1 ; 11$ & $1 ; 9$ & $2 ; 5$ & $1 ; 9$ & $2 ; 3$ \\
\hline number marking & $2 ; 4$ & $1 ; 9$ & $2 ; 5$ & $1 ; 9$ & $2 ; 3$ \\
\hline
\end{tabular}

The data from Christos and Janna reveal a stage in which both functional categories of the nominal domain are inoperative in the children's production. Interestingly, case/number 
marking in nouns seems to correlate with $\mathrm{MLU}^{13}$ values of the children's speech. The MLU values of Christos from 1;7 to 1;10 and of Janna at 1;11 are 1.5 or lower. On the other hand, the MLU values of the children that use case/number marking in nouns are higher than 1.5.

Data from the speech of Christos show that case may develop separately from number marking, since case emerges prior to number marking. Under the assumption that case/number marking provide evidence for the existence of FP in child speech, the FP should be operative at the age of $1 ; 11$ in the speech of Christos, at 1;9 in the speech of Spiros, at 2;5 in the speech of Janna, at 1;9 in the speech of Mairi, and at 2;3 in the speech of Maria.

\subsection{Acquiring the Possessive Construction}

The word-order Possessor $>$ Possessum in the MG Possessive Construction involves movement of the possessor to the specifier of the DP (or to the specifier of a FocP or TopP) (see Section 3.2). Thus, the acquisition of the Possessive Construction can provide evidence for the availability of the Left Periphery of the DP in child speech.

The development of the word-order in the Possessive Construction can be divided into three stages on the basis of the first use of each word-order in the speech of the children observed in this study, i.e. Stage 0,1 and 2. Consider Table 6. All three stages have been identified in the speech of Christos and Mairi, to which the data from the other children have been matched.

Table 6: Acquisition of word-order in the Possessive Construction

\begin{tabular}{|c|c|c|c|c|c|c|}
\hline & word-order & Christos & Spiros & Janna & Mairi & Maria \\
\hline Stage 0 & Possessor & $1 ; 10$ & & $1 ; 11$ & $1 ; 9$ & \\
\hline Stage 1 & Possessum $>$ Possessor & $1 ; 11$ & $1 ; 9$ & $2 ; 9$ & $2 ; 3$ & $2 ; 3$ \\
\hline Stage 2 & Possessor $>$ Possessum & $2 ; 0$ & & & $2 ; 9$ & $2 ; 9$ \\
\hline
\end{tabular}

13 MLU = Mean Length of Utterance. MLU values have been calculated on the basis of words and not on the basis of morphemes. For a discussion on calculating MLU in languages with rich morphology, see Stephany (1985). 
When they want to express a possessive relation, three out of five children, i.e. Christos, Janna and Mairi, initially use bare possessors, as in example (26) below.

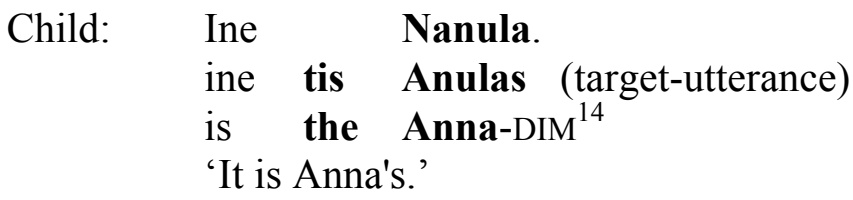

The use of bare possessors is grammatical in adult MG. However, due to the lack of an overt possessum, it is not possible to derive any conclusions as to whether the children under investigation can use both word-orders of the Possessive Construction at that stage.

The first utterances of the consisting of both possessor and possessum involve in the speech of all children the order Possessum > Possessor, as in example (27) below.

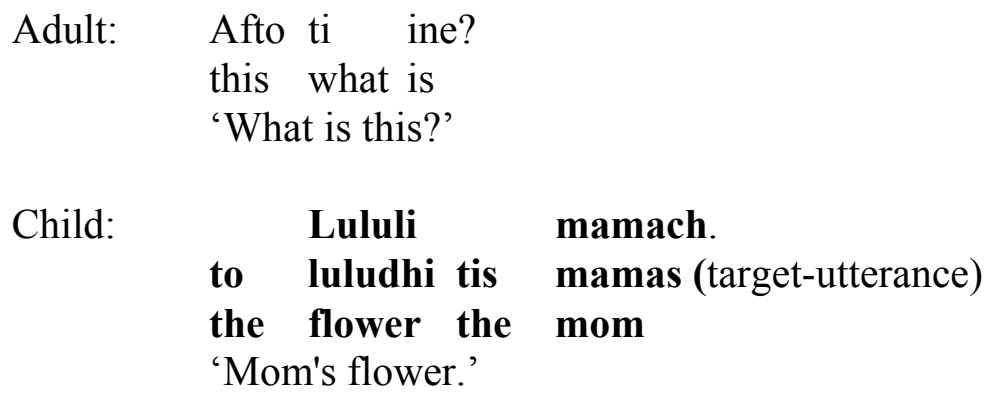

None of the children used simultaneously both word-orders or the order Possessor $>$ Possessum prior to the order Possessum $>$ Possessor.

Stage 2 is defined by the first use of the order Possessor $>$ Possessum. From this point onwards, children use both word orders. Consider example (28) below.

(28) Child:

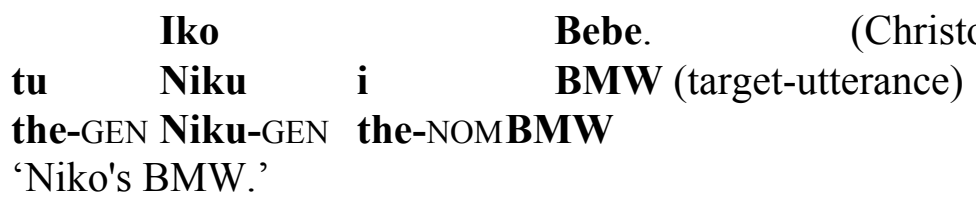

This stage is observed in the speech of three out of five children, i.e. Christos, Mairi and Maria. Janna and Spiros use only the word-order Possessum > Possessor. For Janna, this may be the result of the fact that she uses mainly possessive pronouns when she wants to

$14 \mathrm{DIM}=$ diminutive 
express possessive relations. ${ }^{15}$ Spiros is the only child, for whom we have recordings only at one point in time, i.e. at the age of 1;9. There are no recordings available at a later age. All children, for whom we have recordings at an age comparable with Spiros, i.e. Christos $(1 ; 9)$, and Mairi $(1 ; 9)$, are at that age no further than in Stage 1 . Thus, in the case of Spiros, lack of data for Stage 2 is very likely to be due to the lack of recordings at a later age.

Summarising, all children under study started initially using the word-order Possessum $>$ Possessor and only later did they use the order Possessum $>$ Possessor. Thus, the wordorder that involves the Core Domain is used prior to the word-order involving the Left Periphery of the nominal domain.

\subsection{The emergence of Determiner Spreading}

Within the analysis of DS adopted in the present study, in order for the child to generate this construction, DPs, CPs and A'-Movement must be available in his/her grammar. More specifically, DPs are needed for the generation of definite articles, a CP is needed as a complement of $\mathrm{D}^{0}$ and two types of $\mathrm{A}^{\prime}$-Movement are necessary for the generation of the two main word-order variations: movement of the adjective to the specifier of the $\mathrm{CP}$, and movement of the lower DP to the specifier of a higher DP (or to the specifier of a FocP or TopP). The use of DS in child speech may, thus, provide evidence that the Left Periphery of the DP is operative in child speech.

Adjectives are attested in the speech of all children under investigation very early. Christos uses adjectives from the first recording available, at the age of 1;7.11. However, the first instance of DS is attested in his speech only at the age of 2;3.21. Moreover, he uses both versions of DS in the same recording, as shown in examples (29) and (30) below.

Child: Ta kani bu to palio to Bede.
tha kani bu to palio to Mercedes
fut-prt do bu the old the Mercedes
'The old Mercedes car will fall down.'

(Christos 2;3.21)

15 In the recordings of Janna there are very few instances of the Possessive Construction (number of tokens $=4$ ). As far as possessive pronouns are concerned, Janna is using them from the first recording available, which is at the age of $1 ; 11$. 
(30)

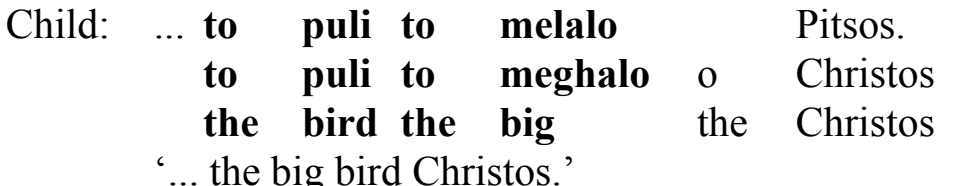

(Christos 2;3.21)

'... the big bird Christos.'

Adjectives are used for the first time in the speech of Mairi at 1;9.19. However, DS emerges in 2;9.15. Consider examples (31) and (32) below, in which Mairi is using the two types of DS in variation.

(31) Child: O mik(r)os o likos pu ine? the small the wolf where is 'Where is the small wolf?'

(Mairi 2;9.15)

$\begin{array}{llllll}\text { (32) Child: } & \text { o } & \text { likos o } & \operatorname{mik}(\mathbf{r}) \mathbf{s} & \text { pu } & \text { ine? } \\ \text { the } & \text { wolf the } & \text { small } & \text { where } & \text { is }\end{array}$

(Mairi 2;9.15)

'Where is the small wolf?'

A similar picture is present in the speech of Maria. Adjectives are attested from the first recording onwards (in 2;3.9), whereas the first instance of DS is attested at the age of 2;9.12, as shown in examples (33) and (34) below.

Child: Thelo na pao athino to to kabine to athino.(Maria 1;9.12)
thelo na pao s-ton kabine ton alithino (target)
want subj-prt go true the to-the toilet the true
'I want to go to the real bathroom.'

$\begin{array}{lllllll}\text { Child: } & \text { Ke } & \text { a } & \text { vro } & \text { ke } & \text { ton } & \text { meghao ton liko. (Maria 1;9.13) } \\ \text { ke tha } & \text { vro } & \text { ke } & \text { ton } & \text { meghalo to } & \text { liko (target-utterance) } \\ \text { and fut-prt find and the } & \text { big the } & \text { wolf } \\ \text { 'And I will find the big wolf.' } & & & \end{array}$

There are no instances of DS in the speech of Spiros and Janna. This is not surprising for Spiros, because there are recordings of his speech only until 1;9. As far as Janna is concerned, it is not clear, if the unavailability of DS in her speech is the result of sampling or if she is not yet able to use this construction.

Crucially, all three children that use DS use simultaneously both types, i.e. the one involving movement of the AP to Spec, $\mathrm{CP}$ and the one involving a further movement of the lower DP to the specifier to a higher DP (FocP, or TopP), as shown in Table 7 below. 
Table 7: First use of adjectives and first use of Determiner Spreading

\begin{tabular}{lcccccc}
\hline \hline first use of & & Christos & Spiros & Janna & Mairi & Maria \\
\cline { 1 - 5 } Adjectives & & $1 ; 7$ & $1 ; 9$ & $1 ; 11$ & $1 ; 9$ & $2 ; 3$ \\
DS with movement to Spec,CP & $2 ; 3$ & - & - & $2 ; 9$ & $2 ; 9$ \\
DS with movement to Spec,CP/Spec,DP & $2 ; 3$ & - & - & $2 ; 9$ & $2 ; 9$ \\
\hline
\end{tabular}

Summarising, in the speech of the children that use this structure, DS emerges much later than their first use of adjectives. Moreover, when children start using DS, both types emerge simultaneously. This indicates that the number of A'-Movement operations required for the generation of DS does not have an effect on the emergence of the two types of DS.

\section{Summary and discussion}

As shown in Section 3, the Left Periphery of the nominal domain consists of the DP, which is parallel to the FinP (see also Haegeman, 2000), and possibly of a FocP and/or a TopP, which project, when focalisation and/or topicalisation are intended. The Core Domain consists of an FP, an inflectional layer corresponding to the IP, and the NP, the lexical layer corresponding to the VP in the clausal domain.

If the acquisition process of the nominal and the verbal domain takes place in a parallel fashion, given the results from Platzack (1999-a), children at an earlier stage of development are expected to pass through a stage in which they do not use structures involving the Left Periphery of the nominal domain, while they use structures involving the Core Domain. The results from the data analysed in this paper are summarised in Table 8.

Table 8: The emergence of structures involving the Core Domain vs. the Left Periphery of the nominal domain

\begin{tabular}{lcccccc}
\hline Emergence of & & Christos & Spiros & Janna & Mairi & Maria \\
\cline { 1 - 4 } \cline { 5 - 7 } Case marking in Nouns (Core Domain) & & $1 ; 11$ & $1 ; 9$ & $2 ; 5$ & $1 ; 9$ & $2 ; 3$ \\
Possessum > Possessor (Core Domain) & & $1 ; 11$ & $1 ; 9$ & $2 ; 9$ & $2 ; 3$ & $2 ; 3$ \\
Possessor > Possessum (Left Periphery) & $2 ; 0$ & - & - & $2 ; 9$ & $2 ; 9$ \\
Determiner Spreading (Left Periphery) & & $2 ; 3$ & - & - & $2 ; 9$ & $2 ; 9$ \\
\hline \hline
\end{tabular}


Table 8 shows that:

1. Structures involving the Core Domain, i.e. case marking in nouns and the order Possessum $>$ Possessor of the Possessive Construction emerge in the speech of the children under investigation earlier than structures involving the Left Periphery, i.e. the order Possessor $>$ Possessum and Determiner Spreading,

2. Determiner Spreading emerges simultaneously or later than the order Possessor $>$ Possessum.

Consequently, data from children acquiring MG show that indeed, structures involving the Left Periphery of the nominal domain emerge later than structures involving the Core Domain.

Under a strong parallelism hypothesis between the acquisition of the nominal and verbal domain, the emergence of phenomena which are related to the Left Periphery of the nominal domain should correlate with the emergence of phenomena which are related to the Left Periphery of the clausal domain. Data on the acquisition of Clitic Left Dislocation (Marinis, 2000-b) partially support this hypothesis.

Clitic Left Dislocation (CLLD) involves a full DP which is generated in the Left Periphery of the clause ${ }^{16}$ and a clitic which is a topic marker and builds an operatorvariable chain with the full DP expressing topichood. ${ }^{17}$ Consider example (35) below.
the-ACC-DEF.ARTICLE
vivlio
to dhiavasa.
'Concerning the book, I read it.'

As far as the acquisition of CLLD is concerned, CLLD emerges in the speech of Christos at the age of 2;1.2 and in the speech of Maria at the age of 2;9, i.e. later than the emergence of case marking in nouns and the order Possessum $>$ Possessor. Consider Table 9 below and example (36) below from Christos.

16 As an IP-adjunct in the analysis of Anagnostopoulou (1994).

17 For the present purpose it is not relevant if the full DP is base generated in its surface position or if it moves from an argumental position within the VP to the dislocated position. What is important is that CLLD involves the Left Periphery of the clausal domain. 
Table 9: The emergence of CLLD vs. case marking in nouns, word-order in the Possessive Construction and Determiner Spreading

\begin{tabular}{lccccc}
\hline \hline emergence of & Christos & Spiros & Janna & Mairi & Maria \\
\cline { 3 - 6 } Case marking in Nouns & $1 ; 11$ & $1 ; 9$ & $2 ; 5$ & $1 ; 9$ & $2 ; 3$ \\
Possessum > Possessor & $1 ; 11$ & $1 ; 9$ & $2 ; 9$ & $2 ; 3$ & $2 ; 3$ \\
Possessor > Possessum & $2 ; 0$ & - & - & $2 ; 9$ & $2 ; 9$ \\
Determiner Spreading & $2 ; 3$ & - & - & $2 ; 9$ & $2 ; 9$ \\
Clitic Left Dislocation & $2 ; 1$ & - & $2 ; 9$ & $2 ; 3$ & $2 ; 9$ \\
\hline \hline
\end{tabular}

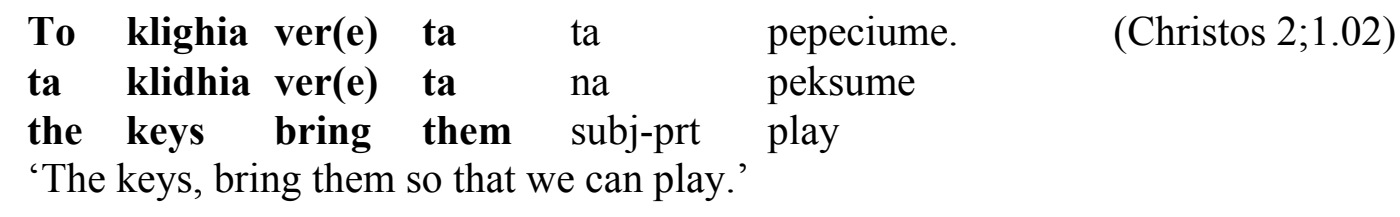

However, in the speech of Janna and Mairi, CLLD is attested simultaneously with the word order Possessum > Possessor. Moreover, Janna uses CLLD although she does not use the order Possessor $>$ Possessum and Determiner Spreading. Thus, the data from Clitic Left Dislocation are not so clear cut. ${ }^{18}$ However, despite the inconsistency in the data from Janna and Mairi, it is crucial that data from the child with the largest number and density of recordings point in the direction that the Left Periphery of the nominal domain develops in parallel to the Left periphery of the clausal domain.

One further result from this study is that a stage has been identified in the speech of the children with the lowest MLU (Christos from 1;7 to $1 ; 10$ and Janna at 1;11), in which nouns have the form of bare stems, i.e. in a very early stage of development there is no evidence for an inflectional layer in the nominal domain. This observation, together with the fact that these two children at that age do not use structures involving the Left Periphery of the nominal domain, indicates that the grammar of the nominal domain used by these children consists only of the lexical layer (NP) and lacks both the inflectional (FP) and the Left Periphery (DP and FocP/TopP).

How can the unavailability of the inflectional layer and/or the Left Periphery of the nominal domain be accounted for?

18 Comparable results are obtained for the acquisition of wh-questions in MG (Marinis, 2000-a). For similar results on the acquisition of wh-questions in French, see Plunkett (2000). 
Within the Principles and Parameters framework, similar results have been interpreted in terms of the presence/lack of functional categories in child grammar (Guilfoyle \& Noonan, 1992; Radford, 1990; Tsimpli, 1992; Powers, 1996, among others) or in terms of underspecification of functional categories (Clahsen, Eisenbeiss \& Penke, 1996; Eisenbeiss, 2000). In the Minimalist Program there is no fixed set of functional categories; Universal Grammar is assumed to provide a set of formal features and a set of operations. The language acquisition process consists of selection of the formal features which are operative in the target grammar, construction of lexical items and refinement of the computational system (Chomsky, 1998). ${ }^{19}$ If Platzack's (1999-b) idea of multiple interfaces is on the right track, the interfaces of Thematic Form, Grammatical Form and Discourse Form are primitives which do not have to be learned. Parameterisation should concern the set of formal features grammaticalised in every language and the way these are encoded in the specific lexical items. Consequently, the exact set of functional projections present in every language should be subject to parameterisation on the basis of the set of formal features grammaticalised in the target language. This being so, development in the three structural domains of the clausal and nominal domain does not have to take place in a uniform way.

As far as the phenomena discussed in this study are concerned, acquisition of the inflectional domain of the DP is reflected in the acquisition of case and number marking in nouns, and is related to the selection of formal features and construction of lexical items. On the other hand, acquisition of the Left Periphery of the nominal domain is reflected in the emergence of the word-order Possessor > Possessum and Determiner Spreading, which are related to the encoding of focalisation and topicalisation. The first type of phenomena are associated with the interface of Grammatical Form, whereas the second type of phenomena with the interface of Discourse Form. The unavailability of the Left Periphery of the nominal domain in child grammar is, in this view, unrelated to the (un)availabilty of

19 Within the Minimalist Program, several ideas have been put forth in order to describe and explain the acquisition process, e.g. Platzack (1996) used the notion of strength, Powers (1996; 2000) used the operation Merge, Roeper $(1996 ; 1999)$ used Merge and the notions Feature Identification, Feature Extraction and Feature Projection, Jakubowicz, Nash, Rigaut \& Gérard (1998) used the notions of Canonical versus Non-Canonical Merge and the feature specification of pronouns, Tsimpli \& Stavrakaki (1999) and Radford (2000) used the notion of $[ \pm$ Interpretable] features. Finally, according to Wexler (1998) the Optional Infinitive Stage is the result of two constraints, the Unique Checking Constraint and Minimize Violations operation. 
the inflectional layer. Since the Left Periphery is related to discourse information, the unavailability of the Left Periphery may reflect difficulties with the pragmatic system operating in child grammar (see also Hyams, 1996; Müller, Crysmann \& Kaiser, 1996; Borer \& Rohrbacher, 1998).

\section{References}

Abney, S. (1987). The English noun phrase in its sentential aspect. Ph.D. Dissertation MIT. Alexiadou, A. (1999). On the Syntax of Nominalization and Possession. Remarks on Patterns of Ergativity. Habilitationsschrift. University of Potsdam.

Alexiadou, A. \& E. Anagnostopoulou (1995). SVO and EPP in Null Subject Languages and Germanic. FAS Papers in Linguistics 4, 1-21.

Alexiadou, A. \& M. Stavrou (1997). Crosslinguistic asymmetries in Noun-Movement: a view from Morphology. ZAS Papers in Linguistics $\mathbf{8}$.

Alexiadou, A. \& M. Stavrou (1998). On derived nominals in Greek. In: B. D. Joseph \& I. Philippaki-Warburton (eds.) Themes in Greek Linguistics II. Amsterdam/Philadelphia: John Benjamins, 101-129.

Alexiadou, A. \& Ch. Wilder (1998). Adjectival Modification and Multiple Determiners. In: A. Alexiadou \& C. Wilder (eds.) Possessors, Predicates and Movement in the DP. Amsterdam: Benjamins, 303-332.

Anagnostopoulou, E. (1994). Clitic dependencies in Modern Greek. Ph.D. Dissertation, University of Salzburg.

Androutsopoulou, A. (1994). The distribution of the definite determiner and the syntax of Greek DPs. In: Proceedings of the 30th Regional Meeting of the Chicago Linguistic Society.

Androutsopoulou, A. (1995). The Licensing of Adjectival Modification. In: Proceedings of the 14th WCCFL. Stanford: CSLI.

Atkinson, M. (1992). Children's Syntax: An Introduction to Principles and Parameters Theory. Oxford/ Cambridge, Mass: Blackwell.

Borer, H. \& B. Rohrbacher (1998) Mind that gap. Systematic omissions in child language and Plato's problem. - In: Chomsky Essays: Essays contributed for Noam Chomsky's 70th Birthday. MIT Press. http://mitpress.mit.edu/chomskydisc/borer3.html

Chomsky, N. (1998). Minimalist Inquiries: The Framework. Ms MIT.

Christofidou, A. (1998). Number or Case first? Evidence from Modern Greek. In: A. Aksu-Koç, E. Erguvanli Taylan, A. Sumru Özsoy \& A. Küntay (eds.) Perspectives on Language Acquisition. Selected papers from the VIIth International Congress for the study of Child Language, 46-59.

Christofidou, A. \& U. Stephany (1997). The early development of case forms in the speech of a Greek boy: a preliminary investigation. Papers and studies in Contrastive Linguistics 33, School of English, Adam Mickiewicz University, Poznán, Poland, 127-139.

Clahsen, H., S. Eisenbeiss \& M. Penke (1996). Lexical Learning in Early Syntactic Development. In: Clahsen, H. (ed.) Generative Perspectives on Language Acquisition. Empirical Findings, Theoretical Considerations, Crosslinguistic Comparisons. Amsterdam: John Benjamins, 129159.

Eisenbeiss, S. (2000). The Acquisition of the DP in German Child Language. In: M.-A. Friedemann \& L. Rizzi (eds.) Acquisition of Syntax. Issues in Comparative Developmental Linguistics.

Grodzinsky, Y. (2000). The neurology of syntax: Language use without Broca's area. In: Behavioral and Brain Sciences 23, 1-71.

Guilfoyle, E. \& M. Noonan (1992). Functional Categories and Language Acquisition. Canadian Journal of Linguistics 37:241-272. 
Haegeman, L. (2000). DP periphery and clausal periphery: possessor doubling in WF. Paper presented in the Peripheries Conference, York, September 2000.

Horrocks, G. \& M. Stavrou (1986).

[One first

approach and interpretation of adjectival modifiers in Modern Greek]. Studies in Greek Linguistics 7, 109-116.

Horrocks, G. \& M. Stavrou (1987). Bounding theory and Greek syntax: evidence for wh-movement in NP. Journal of Linguistics 23, 79-108.

Hyams, N. (1996) The underspecification of functional categories in early grammar. - In: Clahsen, $\mathrm{H}$ (ed.) Generative perspectives on language acquisition. Empirical findings, theoretical considerations \& cross-linguistic comparisons. Amsterdam: John Benjamins, 91-127.

Jakubowicz, C., L. Nash, C. Rigaut \& C.-L. Gérard (1998) determiners and Clitic Pronouns in French-Speaking Children with SLI. Language Acquisition 7, 113-160.

Karanassios, G. (1990).

. [The clausal dimension of the NP]. Studies in Greek Linguistics 11, 175-194.

Kayne, R. S. (1994). The antisymmetry of syntax. MIT Press.

Kilani-Schoch, M., A. de Marco, A. Christofidou, M. Vassilakou, R. Vollmann \& W. Dressler (1997) On the demarcation of phrases in early morphological acquisition in four languages. Papers and studies in Contrastive Linguistics 33, School of English, Adam Mickiewicz University, Poznan, Poland, 15-32.

Kolliakou, D. (1998). Linkhood and Multiple Definite Marking. In: Proceedings of FHCG'98. Kourmoulis, G. (1964).

[Morphological development in Modern Greek]. EEFSPA 15, 9-22.

Lebeaux, D. (1988). Language Acquisition and the Form of the Grammar. Ph.D. Dissertation. University of Massachusetts Amherst.

MacWhinney, B. \& C. E. Snow (1985). The child language data exchange system. Journal of Child Language 12, 271-296.

Marinis, T. (2000-a). The Acquisition of the DP in Modern Greek. Ph.D. Dissertation. University of Potsdam.

Marinis, T. (2000-b). The Acquisition of Clitic Objects in Modern Greek: Single Clitics, Clitic Doubling, Clitic Left Dislocation. ZAS Working Papers 15.

Marinis, T. (2001). Feature Specification in the Modern Greek DP: Acquiring Reference, Case and Agreement. In: Proceedings of the 4th International Conference on Greek Linguistics. Nicosia, September 1999.

Müller, N., B. Crysmann \& G. A. Kaiser (1996) Interactions between the Acquisition of French Object Drop and the Development of the C-System. Language Acquisition 5 (1), 35-63.

Penner, Z. \& N. Müller (1992). On the early stages in the acquisition of finite subordinate clauses. The syntax of the so-called preconjunctional subordinate clauses in German, Swiss German, and French. Geneva Generative Papers 0, no. 2, 163-181.

Platzack, C. (1996). The Initial Hypothesis of Syntax: A Minimalist Perspective on Language Acquisition and Attrition. In: H. Clahsen (ed.) Generative Perspectives on Language Acquisition. Empirical Findings, Theoretical Considerations, Crosslinguistic Comparisons. Amsterdam: John Benjamins, 369-414.

Platzack, C. (1999-a). The Vulnerable C-domain. Ms. Lund University, Dept. of Scandinavian Linguistics.

Platzack, C. (1999-b). Multiple Interfaces. Ms. Lund University, Dept. of Scandinavian Linguistics.

Plunkett, B. (2000). Paper presented in the Peripheries Conference, York, September 2000.

Powers, S. M. (1996). The Growth of the Phrase marker: Evidence from Subjects. Ph.D. Dissertation. University of Maryland.

Powers, S. M. (2000). A Minimalist Account of Phrase Structure Acquisition. In: G. Alexandrovia $\&$ O. Arnaudova (eds.) The Minimalist Parameter. Selected Papers from the Ottawa Linguistics Forum, Current Issues in Linguistic Theory, John Benjamins.

Radford, A. (1990). Syntactic Theory and the Acquisition of English Syntax. Basil Blackwell. 
Radford, A. (2000). Children in search of perfection: Towards a minimalist model of acquisition. Essex research reports in linguistics 34, 57-74.

Ralli, A. (1994). Feature representations and feature-passing operations in Greek nominal inflection. In: Proceedings of the $8^{\text {th }}$ Symposium on English and Greek Comparative Linguistics.

Ralli, A. (1998). On the morphological status of inflectional features: evidence from Modern Greek.

Rice, M. \& K. Wexler (1996). Towards tense as a clinical marker of Specific Language Impairment in English-speaking children. Journal of Speech and Hearing Research 39, 1239-1257.

Ritter, E. (1991). Two Functional Categories in Noun Phrases: Evidence from Modern Hebrew. In: S. Rothstein (ed.) Perspectives on Phrase Structure: Heads and Licensing. New York (Academic Press), 37-62.

Rizzi, L. (1997). The Fine Structure of the Left Periphery. In: L. Haegeman (ed.) Elements of Grammar. Handbook in Generative Syntax. Dordrecht: Kluwer, 281-337.

Roeper, T. (1996). The role of Merger Theory and Formal Features in Acquisition. In: H. Clahsen (ed.) Generative Perspectives on Language Acquisition. Empirical Findings, Theoretical Considerations, Crosslinguistic Comparisons. Amsterdam: John Benjamins, 415-449.

Roeper, T. (1999). Finding fundamental operations in language acquisition: Formal Features as triggers. In: B. Hollebrandse (ed.) New Perspectives on Language Acquisition. G.L.S.A. University of Massachusetts, Amherst.

Stavrou, M. (1996). Adjectives in Modern Greek: an instance of predication, or an old issue revisited. Journal of Linguistics 32, 79-112.

Stephany, U. (1985). Aspekt, Tempus und Modalität: Zur Entwicklung der Verbalgrammatik in der neu-griechischen Kindersprache. [Aspect, tense, and modality: The development of grammar in young Greek children]. Gunther Narr, Tübingen.

Stephany, U. (1997). The Acquisition of Greek. In: D. I. Slobin (ed.) The crosslinguistic study of language acquisition 4. Hillsdale, NJ: Erlbaum, 183-333.

Szabolcsi, A. (1994). The Noun Phrase. In: F. Kiefer \& K. E. Kiss (eds.) The Syntactic Structure of Hungarian. Academic Press, 179-274.

Theophanopoulou-Kontou, D. (1973). Acquisition of noun morphology by children learning Greek as a native language. Master's Thesis, Ohio State University, Columbus.

Thomadaki, E. (1994). Inflection]. Ph.D. University of Athens.

) [Problems of the Modern Greek Morphology (Noun

Tsimpli, I.-M. (1992). Functional Categories and maturation: The prefunctional Stage of Language Acquisition. Ph.D. Dissertation. University College London.

Tsimpli, I.-M. \& S. Stavrakaki (1999). The effects of a morphosyntactic deficit in the determiner system: The case of a Greek SLI child. Lingua 108, 31-85.

Wexler, K. (1996). The Development of Inflection in a biologically based theory of Language Acquisition. In: M. L. Rice (ed.) Toward a genetics of language. Mahwah, NJ: Lawrence Erlbaum, 113-144. 